\title{
Diabetes Mellitus ve Osteoporoz
}

\section{Diabetes Mellitus and Osteoporosis}

\author{
Alev Eroğlu Altınova, ilhan Yetkin
}

Gazi Üniversitesi Tıp Fakültesi, Endokrinoloji ve Metabolizma Bilim Dalı, Ankara, Türkiye

\section{Özet}

Diabetes Mellitus (DM) ve osteoporoz özellikle orta yaşı ve yaşlı popülasyonda morbidite ve mortaliteye yol açan önemli sağlık problemleridir. DM'lu hastalarda artmış fraktür riski bildirilmektedir. Fakat DM ve osteoporoz ilişkisinde altta yatan kompleks mekanizmalar halen net değildir. Bu makalede Tip 1 ve Tip 2 DM ve osteoporoz birlikteliği, diabetik komplikasyonların ve DM tedavisinde kullanılan ilaçların osteoporoza etkileri tartışılmıştır. (Türk Osteoporoz Dergisi 2011;17:96-9)

Anahtar kelimeler: Diabetes mellitus, osteoporoz, kırık, kemik mineral dansitesi

\section{Summary}

Diabetes mellitus (DM) and osteoporosis are serious health problems that cause morbidity and mortality, especially in middle-aged and elderly population. An increased fracture risk has been reported in patients with DM. However, the complex mechanisms underlying the relationship between DM and osteoporosis are still unclear. In this article, coexistence of type 1 and type 2 diabetes and osteoporosis as well as the effects of diabetic complications and antidiabetic treatments on osteoporosis are discussed. (Turkish Journal of Osteoporosis 2011;17:96-9)

Key words: Diabetes mellitus, osteoporosis, fracture, bone mineral density

\section{Giriş}

Diabetes Mellitus (DM) dünya çapında insidansı hızla artan önemli bir metabolik hastalıktır. Yaşlanmayla birlikte görülme sıklığı artan osteoporoz ise ortalama yaşam süresinin giderek artmasıyla ciddi bir sağlık problemi olarak kendini göstermektedir. Her iki hastalık da özellikle orta yaşı ve yaşlı popülasyonda sonuçları itibariyle morbidite ve mortaliteye yol açabilmektedir. Bundan dolayı DM ve osteoporoz ilişkisi ve altta yatan mekanizmalar halen gündemde olan bir konudur. Deneysel ve klinik çalışmalar, DM ile ilişkili kemik anormalliklerinin senil veya postmenopozal osteoporozdan kısmen de olsa farklı olduğunu bildirmektedir (1). DM'da her 2 cinsiyette ve özellikle kalçada fraktür riski artmış olup, yeni kemik oluşumu ve kemik mikromimarisindeki bozulmalar ve sonuç olarak kemik kalitesinde azalma bundan sorumlu tutulmaktadır (1-3). Fakat bu artmış fraktür riskini izah edecek patogenetik mekanizmalarla ilgili data yeterli değildir.

DM'lu hastalardaki osteoporotik fraktür gelişiminde bazı risk faktörleri vardır. Bu risk faktörleri Tablo 1'de sıralanmıştır (4).
DM'un kemiğe olumsuz etkilerinin olası mekanizmaları aşağıda verilmiştir $(5,6)$.

- Negatif kalsiyum dengesine yol açan artmış üriner kalsiyum ekskresyonu (Hiperkalsiüri hiperglisemiye sekonder olarak gelişmektedir) ve kalsiyumun azalmış intestinal emilimi

- Bozulmuş renal fonksiyon

- Fonksiyonel hipoparatiroidizm

- Vitamin D metabolizmasındaki değişiklikler (diabetik nefropatili hastalarda daha belirgin)

- Insülin ve insülin benzeri büyüme faktörleri

- Obezite

- Kollajende artmış ileri glikozilasyon son ürünleri (AGE)'ler

- Mikroanjiyopati

Insülin kemik için de anabolik bir hormondur ve yokluğu veya fazlalığı DM'lu hastalarda kemik metabolizmasını etkiler. Insülinin osteoblast ve osteoklastlar üzerine direk etkisi vardır. Ayrıca seks hormon bağlayıcı globulini azaltıp, serbest östrojen ve testosteron düzeylerini artırarak kemik mineral dansitesi (KMD)'ni artırıcı yönde etkisi vardır. Bunun yanında IGF bağlayıcı peptid-1 
(IGFBP-1)'i baskılayarak osteoblastların IGF-1'e duyarlılığını $\operatorname{artırır}(7)$.

Kemik iliği mezenkimal kök hücreleri hem osteoblastların hem de adipositlerin kaynağıdır. Yağ hücrelerinden salgılanan leptin ve adiponektinin enerji homeostazı yanında iskelet üzerine de etkileri olabilir. Bunun yanında kemik hücrelerinin aktivitesi sadece kemiğin yeniden yapılanması ile sınırlı olmayıp yağ dokusu duyarlılığı ve insülin sekresyonu ile de ilişkili olabilir (8). Yapılan klinik çalışmalar Tip 2 DM'da kemikteki bozulmuş kollajen çapraz bağlarının artmış fraktür riskinde önemli rolü olabileceğini belirtmektedir (9). Bununla ilgili olarak ratlara vitamin K2 verilmesinin tip 2 DM'da kemik kalitesine yararlı etkileri olabileceği rapor edilmiştir (10). Bu yararlı etkiyi serum osteokalsin düzeyinde artış, kollajen çapraz bağlarında düzelme ve kemik kuvvetini artırarak yaptığı söylenmektedir.

Hem Tip 1 hem de Tip 2 DM'lu hastalardaki düşük D vitamini düzeylerinin de diabetteki osteoporoz gelişimine katkıda bulunduğu belirtilmektedir (7).

\section{Glisemik Kontrol ve Osteoporoz}

Diabette bozulmuş glukoz metabolizması sonucu gelişen artmış AGE ve onların reseptörlerinin (RAGE) kemik metabolizması ve kemik gücünde önemli etkileri vardır (5). Tip 1 kollajen gibi çeşitli kemik proteinlerinin nonenzimatik glikozilasyonu kemik kalitesinin bozulmasına sebep olmaktadır (11). Öte yandan yüksek pentosidin düzeylerinin diabetik hastalardaki artmış fraktür riskinde rolü olabileceğini bildiren çalışmalar mevcuttur (12). Ayrıca osteoblastlar ve yağ hücreleri tarafından sekrete edilen osteokalsin ve adiponektinin de kemik, glukoz/yağ metabolizması arası etkileşimde rol oynayabileceği bildirilmektedir (13) (Şekil 1).

\section{Tablo 1. DM'lu hastalardaki osteoporotik fraktürler için risk}

\section{faktörleri}

\section{Diabete bağlı}

- Tip 1 diabetes mellitus

- Kötü glisemik kontrol

\section{Diabetin komplikasyonlarına bağlı \\ - Nöropati (mobilitenin azalması) \\ - Diabetik daire \\ - Nefropati \\ - Anjiyopati (kemiğe giden kan akışında değişiklikler sonucu)}

\section{Diabet ile ilişkili hastalıklara bağlı}

- Çöliak hastalığ

- Amenore

- Gecikmiş puberte

- Yeme bozuklukları

\section{Düşme riski}

- Hipoglisemi atakları

- Nokturi

- Görme bozukluğu (retinopati veya katarakta bağı)

- Denge bozukluğu (nöropati, ayak ülseri veya amputasyona bağı)

- Ortostatik hipotansiyon

- Kerioartropatiye bağı bozulmuş eklem motilitesi
Bazı çalışmalarda kötü glisemik kontrolün DM'lu hastalarda osteoporoz ile pozitif ilişkili olduğu gösterilmiştir (7). Tip 1 DM'lu hastalarda yapılan bir çalışmada, glisemik kontrolün artmış fraktür prevalansı ile ilişkili olduğu, bunun yanında KMD ile lişkili olmadığı rapor edilmiştir (14). Yorum olarak yazarlar hipergliseminin KMD'den bağımsız olarak kemik gücüne olumsuz etkisi olabileceğini belirtmişlerdir.

\section{Tip 1 DM ve Osteoporoz}

Tip 1 DM'lu hastalarda yapılan çalışmaların hepsinde olmasa da çoğunda KMD'de düşme saptanmıştır (1). Genel olarak Tip 1 DM'lu hastaların \%50'sinden fazlasında kemik kaybı olduğu, yaklaşık \%20'sinde de KMD değerlerinin -2,5 SD değerinin altında olduğu tahmin edilmektedir (15). Yakın zamanda yapılmış bir metanalizde; tip 1 DM'da KMD'deki azalmayla birlikte kalça kırığı riskinin anlamlı olarak arttığı gösterilmiştir (5). Bununla birlikte Tip 1 DM'daki artmış fraktür riskinin sadece KMD'deki azalmayla açıklanamayacağı, kemik kalitesindeki azalmanın esas etken olabileceği belirtilmektedir (9).

Tip 1 DM ve osteoporoz ilişkisinde cinsiyetin etkisi konusu tartışmalıdır. Fakat çoğu çalışmalar erkeklerde riskin daha fazla olduğu yönündedir (7). 5 yıllık prospektif bir çalışma olan Fremantle çalışmasında erkeklerde femur boynundaki KMD düşüşünün daha yaşlı postmenopozal tip 2'DM'lu kadınlarla benzer olduğu bulunmuştur (16). Aynı çalışmada Tip 1 DM'lu erkeklerde kemik rezorbsiyonunda artmayla ilişkili olarak inefektif bir kemik yapımının olduğu belirtilmiştir. Osteoporoz ve cinsiyet ilişkisinde kadınlarda oral kontraseptif kullanımının ve menopoz öncesi yüksek östrojen düzeylerinin olumlu katkısı olabileceği bildirilmektedir (1).

\section{Tip 2 DM ve Osteoporoz}

Tip 2 DM'daki KMD değişiklikleri konusu tartışmalıdır. Yüksek, normal ve düşük saptanan çalışmalar vardır (7). Bununla birlikte Tip 2 DM'lu hastalardaki KMD değişiklikleri üzerine yapılan en büyük çalışmalardan biri olan Rotterdam çalışmasında,

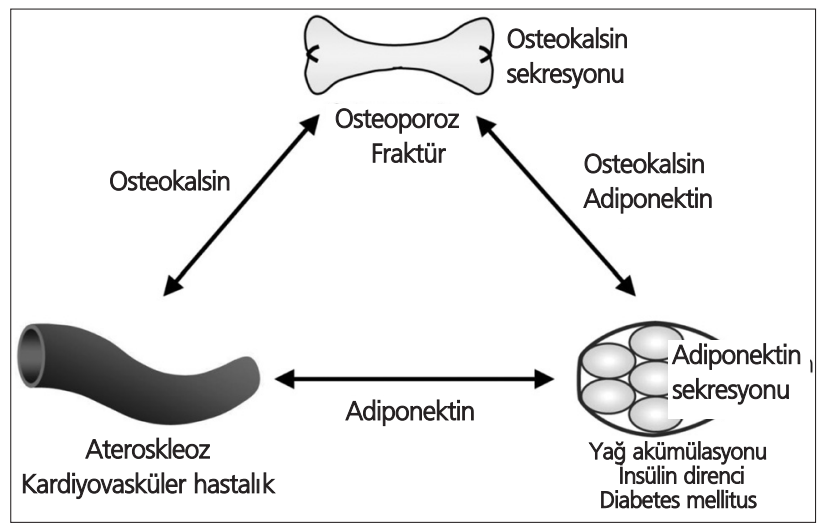

Şekil 1. Kemik metabolizması ve glukoz/yağ metabolizması arası etkileşim (Yamaguchi T, Endocrine Journal, 2011,58:613-624) 
nondiabetiklere oranla diabetik hastalarda hem kalça hem vertebrada \%3 oranında artmış KMD değerleri saptanmıştır (17). KMD'deki bu artış vücut kitle indeksi (VKi) ve yaş gibi karıştırıcı faktörlerin düzeltilmesinden sonra da anlamlılığını kaybetmemiştir. Başka bir çalışmada Tip 2 DM'lu hastaların KMD değerleri yüksek olmasına rağmen artmış kemik fraktürü riski taşıdıkları rapor edilmiştir (18). Popülasyon bazlı bir çalışmada Tip 2 DM'lu hastalarda hem vertebra hem kalçada artmış fraktür riski saptanmakla birlikte kalçadaki riskin daha belirgin olduğu bildirilmiştir (19).

Tip 2 DM'daki sıklıkla artmış VKi'nin koruyucu bir faktör olabileceği bildirilmektedir. Bir metaanalizde, VKI'nin Tip 2 DM'lu hastalarda en etkili faktör olduğu saptanmıştır (5). Tip 1 DM ile VKi arasında ise böyle bir ilişki bulunmamıştır (20).

\section{Diabetik Komplikasyonlar ve Osteoporoz}

Diabetik retinopati, nefropati ve nöropati gibi komplikasyonların artmış fraktür riski ile ilişkili olabileceği belirtilmektedir $(7,19)$. Diabetik komplikasyonları olan hastalarda KMD'nin düşük ve fraktür riskinin artmış olduğu bulunmuştur (5). Yeni yapılan bir çalışmada DM süresi daha uzun ve renal fonksiyon bozukluğu ve retinopatisi olan Tip 2 DM'lu hastalarda osteoporoz ve vertebral fraktür prevalansının daha yüksek olduğu gösterilmiştir (21). Retinopati egzersizi dolayısıyla kas kitlesini azaltarak ve görme bozukluğuna neden olarak; nefropati kemik metabolizmasını etkileyerek; nöropati egzersizi azaltarak ve anjiyopati direk olarak kemik vaskülarizasyonunu etkileyerek rol oynayabilir (7). Komplikasyonlara bağlı olarak artmış düşme riskinin fraktür riskinde artışa katkısı olabileceği de belirtilmektedir (5). Bununla birlikte diabetik komplikasyonlarla KMD arasında ilişki saptamayan çalışmalar da mevcuttur (7).

\section{DM Tedavisi ve Osteoporoz}

Insülinin kemik açısından anabolik etkisi olsa da insülin tedavisinin iskelet üzerindeki etkisi tartışmalıdır. Bazı çalışmalarda insülin tedavisinin düșme sıklığı ve fraktür riskinde artış ile ilişkili olduğu saptanmıştır $(1,19)$. Fakat insülin tedavisi alan hastalarda hastalığın daha ciddi olduğu ve komplikasyonların daha fazla olduğu unutulmamalıdır. Oral antidiabetik ilaçlardan tiazolidinedion (TZD) grubu (PPARgamma agonisti) ilaçlardan olan pioglitazonun osteoblast farklılaşmasını azaltıp, adiposit farkılaşmasını artırarak kemik üzerine potansiyel zararlı etkilerinin olabileceği bildirilmektedir (1). Özellikle kadınlarda TZD grubu ilaçların artmış kemik kaybı ve fraktür riski ile ilişkili olduğu rapor edilmiştir $(1,22)$. Dahası pioglitazon kullanımının kemik döngü belirteçlerinde değişiklikler ve azalmış KMD ile ilişkili olduğu saptanmıştır (4). Öte yandan oral antidiabetik ilaçlardan metformin veya sülfonilürenin fraktür riskini azaltabileceği konusunda çalışmalar mevcuttur $(1,19)$. Deneysel çalışmalarda daha yeni ilaçlardan olan GLP-1 agonistleri ve DPP-4 inhibitörlerinin GLP-1'in kemik üzerine olan potansiyel anabolik ve antirezorbtif etkileri olabileceği bildirilmektedir (1). Fakat bununla ilgili uzun dönem verilere intiyaç vardır.

\section{Sonuç}

DM ve osteoporoz ilişkisinde kompleks mekanizmalar rol oynamaktadır. Genel eğilim Tip 1 DM'lu hastalarda KMD'de azalma, bunun tersine tip 2 DM'lu hastalarda KMD'de artış olduğudur. Bununla birlikte her 2 tip diabette de özellikle kalçada fraktür riski artmıştır. Bu da DM'lu hastalarda kemik fraktürlerini önlemede spesifik koruyucu ve tedavi edici stratejilerin geliştirilmesi gerekliliği ortaya koymaktadır. Bu nedenle DM'lu hastaların takibinde kemik sağlığının da değerlendirilerek fraktürlerin önlenmesi, kemik dansitesinin düzeltilmesi ve düşme risklerinin azaltılması önemlidir.

\section{Kaynaklar}

1. Merlotti D, Gennari L, Dotta F, Lauro D, Nuti R. Mechanisms of impaired bone strength in type 1 and 2 diabetes. Nutr Metab Cardiovasc Dis 2010;20:683-90.

2. Yaturu S. Diabetes and skeletal health. J Diabetes 2009:1:246-54.

3. Räkel A, Sheehy $O$, Rahme E, LeLorier J. Osteoporosis among patients with type 1 and type 2 diabetes. Diabetes Metab 2008;34:193-205.

4. Brown SA, Sharless JL. Osteoporosis: An Under-appreciated Complication of Diabetes. American Diabetes Association Web Page. Clinical Diabetes 2004;22:10-20.

5. Vestergaard P. Discrepancies in bone mineral density and fracture risk in patients with type 1 and type 2 diabetes-a meta-analysis. Osteoporos Int 2007:18:427-44.

6. Isidro ML, Ruano B. Bone disease in diabetes. Curr Diabetes Rev 2010:6:144-55

7. Issa C, Zantout MS, Azar ST. Osteoporosis in men with diabetes mellitus. J Osteoporos 2011:2011:651867.

8. de Paula FJ, Horowitz MC, Rosen CJ. Novel insights into the relationship between diabetes and osteoporosis. Diabetes Metab Res Rev 2010;26:622-30

9. Saito M, Marumo K. Collagen cross-links as a determinant of bone quality: a possible explanation for bone fragility in aging, osteoporosis, and diabetes mellitus. Osteoporos Int 2010:21:195-214.

10. Iwamoto J, Sato Y, Takeda T, Matsumoto H. Bone quality and vitamin K2 in type 2 diabetes: review of preclinical and clinical studies. Nutr Rev 2011:69:162-7.

11. Vashishth D, Gibson GJ, Khoury JI, Schaffler MB, Kimura J, Fyhrie DP. Influence of nonenzymatic glycation on biomechanical properties of cortical bone. Bone 2001;28:195-201.

12. Schwartz AV, Garnero P, Hillier TA, Sellmeyer DE, Strotmeyer ES, Feingold KR et al. Health, Aging, and Body Composition Study. Pentosidine and increased fracture risk in older adults with type 2 diabetes. J Clin Endocrinol Metab 2009;94:2380-6.

13. Yamaguchi T, Sugimoto T. Bone metabolism and fracture risk in type 2 diabetes mellitus. Endocr J 2011;58:613-24.

14. Neumann T, Sämann A, Lodes S, Kästner B, Franke S, Kiehntopf M et al. Glycaemic control is positively associated with prevalent fractures but not with bone mineral density in patients with Type 1 diabetes. Diabet Med 2011;28:872-5.

15. McCabe LR. Understanding the pathology and mechanisms of type I diabetic bone loss. J Cell Biochem 2007;102:1343-57.

16. Hamilton EJ, Rakic V, Davis WA, Paul Chubb SA, Kamber N, Prince RL et al. A five-year prospective study of bone mineral density in men and women with diabetes: The Fremantle Diabetes Study. Acta Diabetol 2011;Epub ahead of print). 
17. van Daele PL, Stolk RP, Burger $H$, Algra D, Grobbee $D E$, Hofman $A$ et al. Bone density in non-insulin-dependent diabetes mellitus. The Rotterdam Study. Ann Intern Med 1995:122:409-14.

18. Schwartz AV, Sellmeyer DE, Ensrud KE, Cauley JA, Tabor HK, Schreiner PJ et al; Study of Osteoporotic Features Research Group. Older women with diabetes have an increased risk of fracture: a prospective study. J Clin Endocrinol Metab 2001;86:32-8.

19. Melton LJ 3rd, Leibson CL, Achenbach SJ, Therneau TM, Khosla S. Fracture risk in type 2 diabetes: update of a population-based study. J Bone Miner Res 2008;23:1334-42.
20. De Laet $C$, Kanis JA, Odén A, Johanson $H$, Johnell O, Delmas $P$ et al. Body mass index as a predictor of fracture risk: a meta-analysis. Osteoporosis Int 2005;16:1330-8.

21. Viégas M, Costa C, Lopes A, Griz L, Medeiro MA, Bandeira F. Prevalence of osteoporosis and vertebral fractures in postmenopausal women with type 2 diabetes mellitus and their relationship with duration of the disease and chronic complications. J Diabetes Complications 2011:25:216-21.

22. Li H, Cui R, Cai H, Wu G, Lv Z, Sheng $C$ et al. The effect of thiazolidinediones on bone mineral density in Chinese older patients with type 2 diabetes. J Bone Miner Metab 2010;28:77-81. 